\title{
MORTE, LUTO E ORGANIZAÇÃO FAMILIAR: À ESCUTA DA CRIANÇA NA CLÍNICA PSICANALÍTICA
}

\author{
Leônia Cavalcante Teixeira*
}

\section{RESUMO}

As especificidades da clínica com crianças pequenas interrogam os conhecimentos já estabelecidos sobre os sintomas e as possibilidades de abordagem psicanalítica. Quando se trata de crianças, a clínica se constitui no entrecruzamento de subjetividades, imprimindo impasses e possibilidades para o paciente, seus pais e o analista. Objetivou-se investigar os efeitos da clínica com crianças no processo de re-configuração da organização familiar. $\mathrm{O}$ estudo de um caso clínico foi privilegiado, tendo sido focalizadas as experiências do luto e seus destinos na malha familiar. A articulação dos sinais que a criança pequena apresenta em uma rede simbólica que possibilite os deslocamentos das manifestações psicossomáticas em direção a alternativas outras de reconstituição subjetiva indica-nos que muito há para ser feito numa análise no campo da prevenção, no qual as intervenções precoces já constituem tratamento propriamente dito.

Palavras-chave: psicanálise, psicossomática, infância, família, asma

\section{AbSTRACT}

DEATH, MOURNING AND FAMILY STRUCTURE: OBSERVATION OF THE CHILD IN CLINICAL PSYCHOANALYSIS

The specificity of clinical work with small children questions the established knowledge about the symptoms and the possibilities of the psychoanalytic approach. When children are concerned, clinical work have in view the crossing of subjectivities, the difficulties and possibilities of the patient, his/her parents and the analyst. The aim of this study is to investigate the effects of clinical work with children in the process of reconfiguring the family structure. The study of a clinical case was favored, focusing on the experience of mourning and its destinies in the family

* Professora Titular do Mestrado em Psicologia da Universidade de Fortaleza; Doutora em Saúde Coletiva (IMS/UERJ); Mestre em Educação (UFC); Psicóloga e psicanalista. 
fabric. The articulation of the signs that the small child presents in a symbolic network which makes the displacement of the psychosomatic manifestations possible in the direction of the other alternatives of subjective reconstruction indicate to us that there is much to be done in an analysis in the field of prevention, in which early interventions already constitute the treatment itself.

Keywords: psychoanalysis, psychosomatic, childhood, family, asthma

A atualidade nos confronta com plurais questões sobre os saberes e as práticas hegemônicos no campo da psicologia e da psicanálise, exigindo o repensar dos pressupostos e conceitos que guiam as diferentes perspectivas de lidar com o psíquico e seus destinos. Considerando que essa postura interrogativa marque os espaços de atuação dos profissionais da área psi, pensamos serem fundamentais a apresentação e a discussão dos modos como nos situamos frente ao sofrimento singular e coletivo. Nesse sentido, o acento do artigo recai na expressão de pontos de vista plurais, e mesmo opostos, sobre algumas vicissitudes do fazer psicológico.

Os fenômenos psicossomáticos constituem uma expressão significativa da clínica psicológica na atualidade. A clínica mostra as atuais facetas dos modos de subjetivação postos em cena pela "psicopatologia somática”, evidenciando como o imaginário da época colore o panorama sintomático dos sofrimentos subjetivos. Ressaltamos que os destinos da emergência do corpo na clínica psicológica situamno como veículo e plataforma do sofrimento, deixando-se falar através das queixas somáticas e da ausência de implicação do sofrente na história do corpo doente.

O campo de investigação do psiquismo na interface com o somático não é recente (Castro, Andrade e Muller, 2006; Teixeira, 2006a), datando dos clássicos gregos e, em especial, ocupando lugar de destaque nas proposiçōes do Corpus hipocraticum (Volich e Ferraz, 1998). Mesmo antes, com a marca do horizonte cosmocêntrico de pensamento, isto é, através da lógica na qual os acontecimentos na vida dos homens, bem como seus destinos, eram explicados pela interferência do poder dos deuses, seus descendentes e privilegiados. Assim, Apolo, Chíron e Esculápio estabelecem uma linhagem cuja característica fundamental sustenta-se nos poderes de cura dos males dos homens (Mello Filho, 1992; Volich e Ferraz, 1998).

A partir de reflexões sobre as novas formas de manifestação dos sintomas na contemporaneidade, os fenômenos psicossomáticos vêm atraindo cuidados teóricos e clínicos, já que constituem um dos modos sustentadores dos processos de subjetivação atuais, questionando a clínica daqueles que não buscam construir quadros diagnósticos e enquadres terapêuticos acolhedores desse tipo de manifestação do mal-estar existencial. Percebe-se que os quadros psicopatológicos teóricos que acentuam a importância do diagnóstico a partir da consideração de doenças psíqui- 
cas sem substrato orgânico e de transtornos somáticos na ausência de determinantes psíquicos não contemplam a amplitude e a radicalidade do sofrimento.

Considerando os campos de apreensão teórica da doença orgânica a partir de concepções da psicossomática e do questionamento desta terminologia e demarcando o estudo das diversas formas de leituras dos fenômenos psicossomáticos, as elaborações teóricas e clínicas aqui expostas pressupõem a articulação entre sofrimento, cultura e subjetividade, focalizando os lugares do corpo na psicanálise e, especialmente, as formas como a doença orgânica se faz presente nas construções clínicas e metapsicológicas de Freud (Freud, 1895/ 1976; Teixeira, 2002, 2006a).

Discutiremos a manifestação psicossomática na primeira infância, tomando como ponto de partida um caso clínico acompanhado em consultório de psicanálise. As especificidades da clínica com crianças pequenas e a escuta do sofrimento trazido por elas e por seus pais às consultas interrogam os conhecimentos já estabelecidos sobre os sintomas e as possibilidades de abordagem psicanalítica. Inicialmente são desenvolvidas considerações sobre o estatuto da manifestação psicossomática, ressaltando a relação doença, corpo e subjetividade. Em um segundo momento, o caso clínico é apresentado e discutido à luz do entrecruzamento entre aspectos das clínicas freudiana e de autores como Dolto (1984), Lacan (1938/ 1987), Mannoni (1999) e Winnicott (1969), dentre outros.

\section{DE QUE TRATA A MANIFESTAÇÃO PSICOSSOMÁTICA?}

A psicossomática psicanalítica se organiza em um discurso que, considerando a já difícil transferência paciente-analista, organiza, por suas possibilidades de escuta, diferentes formas de demanda do sofrimento e de seus paradoxos. Freud em "Sobre o início do tratamento. Novas recomendações sobre a técnica da psicanálise I", escreve que "a força motivadora primária da terapia é o sofrimento do paciente e o desejo de ser curado que deste se origina” (Freud, 1913/1976: 186). Lacan, posteriormente, trata as vicissitudes da aderência terapêutica considerando que demanda de cura não equivale, necessariamente, ao desejo de curar (Lacan, 1966/1998).

A relação entre doença e subjetividade apresenta como o corpo do desejo se põe à mercê de somatizações, erguendo a problemática da eclosão dos fenômenos psicossomáticos. Lidar clinicamente com corpos doentes que buscam a saúde como sinônimo de vida sem se implicarem como sujeitos no adoecer presume considerar o corpo na sua amplitude semântica, nos campos da biomedicina, dos saberes e práticas psi. 
A enfermidade implica uma certa condição de vida que interroga a saúde. Vida e saúde não são campos que se equivalem. O processo da vida inclui a doença e a presença iminente da morte, embora o imaginário moderno rechace as experiências de sofrimento como contra-ideais. A doença e os compromissos que esta exige do sujeito são considerados pela biomedicina como contrastantes com os ideais de saúde, de qualidade de vida e de longevidade (Teixeira, 2002).

Lidar com o corpo sendo este percebido na interseção de subjetividades e, assim, tornado legível no jogo simbólico, que não se reduz ao exercício funcional do biológico, constitui condição sine qua non para a visibilidade do indivíduo em sua complexidade, ou seja, dos modos como o humano se transforma em sujeito.

O sentido de patológico merece ser evocado como operador de questionamentos de visões maniqueístas do processos de saúde e doença, sendo o adoecer entendido como desventurança, infelicidade, como desestabilizador do processo vital. Entender o pathos (Berlinck, 2000; Ceccarelli, 2005) no que ele apresenta de originário parece ser uma arma teórico-clínica para enfrentar pontos de vista que expulsam o mal-estar, autêntica manifestação do sofrimento e das vicissitudes do existir humano. O pathos se situa no campo do excesso, da desmesura, do sofrimento e da paixão que se apossam do homem, exigindo dele passividade, alterando sua natureza, transformando-o em um ator que experimenta algo da ordem da exuberância, da falta de medida.

Nesse contexto, a relação tipicamente moderna saúde/doença perde força em detrimento de uma questão ética na qual o construir-se como sujeito inclui as noções de vida e de morte como valores. A consideração do corpo nas relações com outros corpos se desvia da concepção de doença como incapacidade, entendendo-a como uma prática de si que se constrói no registro político das demandas, do entrecruzamento de subjetividades. As relações entre doente, doença e medicina se instituem, portanto, na trama histórica das concretudes do existir humano (Canguilhem, 2000; Foucault, 2006).

Considerando que os fenômenos psicossomáticos constituem uma das queixas mais freqüentes nas consultas psiquiátricas e psicológicas, a investigação sobre o tema ocupa lugar de destaque na agenda dos pesquisadores na área da saúde. As manifestaçôes psicossomáticas acometem sujeitos em sua economia psíquica, daí exigirem alternativas de apreensão teórica que não se limitem à leitura do corpo como organismo.

A psicopatologia somática como um campo de desafios à clínica constitui-se pela não-implicação do sujeito em seu sofrer, sendo este figurado pelos destinos de um corpo lesionado e dolorido. A construção, pelo sujeito, de discursos sobre 
sua dor mostra-se suprimida, padecendo o corpo em sua concretude. Quando abordamos manifestações psicossomáticas em crianças, urge ressaltar a importância da consideração do lugar dos pais na construção da dinâmica do adoecimento do(a) filho(a).

Compartilhamos com a distinção entre manifestação psicossomática da primeira infância e fenômeno psicossomático elaborada por Infante (1998) quando escreve que o último "revela uma fixação de gozo que não tem correspondência no bebê" (Infante, 1998: 149). Devido a esta justificativa conceitual, esclarecemos que o termo manifestação será privilegiado, neste escrito, quando o sofrimento da criança for focalizado, sendo o uso da nomenclatura fenômeno psicossomático empregado de modo amplo.

Um fenômeno é dito psicossomático quando os sintomas não se inscrevem no corpo histérico (Freud, 1895/1976), mas no corpo médico, no corpo que demanda respostas e explicações à fisiopatologia. Daí constituir a psicossomática um campo de interfaces entre saberes e práticas médicas, psicológicas e psicanalíticas. Kupfer e Voltolini, ao estudarem as tensões existentes entre os discursos psicanalíticos e médicos, escrevem:

a clínica médica, ordinariamente, não pode senão guiar-se por aquilo que o médico consegue observar objetivamente, aquilo que o exame clínico ou laboratorial deixa transparecer. Não pode jamais guiar-se pela leitura que o próprio doente faz de sua doença, uma vez que este se equivoca, ou mesmo pode não a perceber (como no caso assintomático de algumas doenças) (Kupfer e Voltolini, 2005: 361) .

Ainda concordando com os autores acima citados quando afirmam que, embora difícil, é possível uma perspectiva dialógica entre o campo psi e a medicina, enfatizamos a necessidade de releitura dos destinos pulsionais quando estes deixam marcas no corpo que não funcionam pela lógica da decifração, mas que se inscrevem lesionando pela patologia: o sujeito se rebela nos registros do corpo somático observado e tratado pelo olhar da medicina.

O soma adoecido mostra-se, transferencialmente, nas sessões de análise pelas queixas, lamentações e narrativas dos périplos médicos percorridos pelo enfermo. É o deslocamento da história da doença para a história do doente que a análise busca. A construção do romance familiar (Freud, 1909/1976) pelo paciente o faz mergulhar, pela transferência, no árduo trabalho de edificação do corpo psicanalítico, corpo que só existe na alteridade, pelo olhar do outro que o desenha sexualmente e que, na análise, pode ser acolhido na rede do amparo subjetivo. 


\section{CONSIDERAÇÕES CLÍNICAS}

Neste texto, apresentamos algumas considerações acerca da análise como espaço de construção subjetiva a partir do acompanhamento de F.E., que, aos oito meses, já sofria de episódios de asma brônquica muito fortes. Após um ano de análise, F.E. passou mais de dois meses fazendo desenhos semelhantes, descrevendo-os como "pessoas que tinham a barriga cheia", "gente que comia demais". Durante este período, vários encontros foram solicitados aos pais. Após uma dessas sessões com toda a família, F.E. teve uma crise asmática que a levou à internação por cinco dias. Depois de duas semanas, F.E. voltou ao consultório e começou a contar histórias com os desenhos de "barriga cheia" que antes fizera. Ela os redesenhava, riscava as barrigas, brigava "com eles ou com elas" (as barrigas).

A mãe P. contou que durante o namoro com o pai de F.E. ficou grávida e, como sua mãe não gostava muito de sua relação com ele, resolveu, com muito custo, "tomar um monte de coisas" e não ter o bebê. Relatou que não podia decepcionar sua mãe que estava doente e que veio a falecer depois de ela já estar casada e F.E. já ter nascido.

P. relata que, durante os dias finais de sua mãe, sofreu muito, dando pouca atenção à filha. P. diz que se lembra da filha dando os primeiros passos apoiada nas beiradas da cama de sua avó enferma: "F.E. ficava sempre perto de mim, eu via tudo e não podia fazer nada. Ela andava, balbuciava, batia palmas, como se quisesse me animar". P. relatou que logo após casar ficou grávida e perdeu naturalmente o bebê, fato que lhe trouxe muita dor. A avó de F.E. ficara muito abalada com a não-continuidade da gravidez da filha.

Os significados da asma e dos aspectos comportamentais, desenvolvimentais e interacionais nela envolvidos despertam a atenção das clínicas médica e psicanalítica. Pesquisas sobre as características do asmático, da personalidade e da família asmáticas (Hames, 1998; Kreisler, 1983, 1999) iluminam fenômenos observáveis importantes: proteção excessiva da mãe, hipersensibilidade afetiva, conflito familiar, pouca agressividade, mudanças fugazes de vínculo, dentre outras. Ao considerar esses estudos, sublinho que, apesar de serem significantes na constituição de um campo teórico-clínico útil na elaboração de estratégias de prevenção e tratamento, opto por caminhar em outra direção. Ou seja, a escuta psicanalítica me coloca questôes diferenciadas que ensaiamos desenvolver e responder através das possibilidades teóricas abertas por Freud (1895/1976, 1900/1976, 1914/ 1976, 1915/1976, 1920/1976, 1923/1976) ao problematizar a constituição do psiquismo, a organização pulsional, o narcisismo e o romance familiar. Ao debru- 
çar-me sobre a asma, também muito me atrai a investigação acerca das representações da respiração (Chiozza, 1997).

A asma brônquica grave de F.E. colocava em cena o que não podia ser falado por P., já que a incomodava como mãe e como filha, por sentir que traíra sua mãe duas vezes. A culpa de P. obstruía os brônquios de sua filha. Com as sessões em que P. falava sobre suas perdas e dores, os brônquios de F.E. começaram a ficar mais dilatados. F.E. continuou em tratamento por um ano e meio, aproximadamente. As crises foram ficando esparsas e os traços obsessivos, também fortes, foram deixando de ser mencionados por sua família.

Em relação às queixas formuladas pelos pais da criança, enfatizamos que todas apresentavam, implícita e muitas vezes explicitamente, um pedido de socorro, uma solicitação de ajuda no sentido de serem eles, os pais, instruídos a como lidar com as dificuldades de seus filhos, bem como de às crianças serem proporcionadas técnicas de correção dessas dificuldades. Nesse sentido, é importante destacar que a queixa, quando mais bem discutida entre pais, criança e analista, ia tomando rumos diferentes e que, durante o processo terapêutico, puderam ser delimitadas especificidades subjetivas que diziam respeito à história de cada um dos pais e do casal parental.

Também pôde ser observada a forte influência da cadeia geracional na constituição dos modos de padecimento da família (Corrêa, 2001; Kaës, 2000; Meira, 2003). Quando enfocamos o lugar da queixa na condução do tratamento, já estamos incluindo a relação criança-pais, já que a fantasmática parental pareceu-nos constituir um pano de fundo no qual as possibilidades de construção de identificações eram apoiadas. É interessante notar que a função do terceiro, tão importante para a estruturação subjetiva (Freud, 1923/1976; Lacan, 1938/1987, 1998; Dolto, 1984), pôde ora ser exercida pelo analista, ora pelo grupo, já que as crianças detinham a possibilidade de intervir junto à dinâmica dos encontros e às outras crianças, participando ou não das atividades acordadas pelo grupo.

A clínica psicanalítica com crianças pequenas propicia o enquadramento clínico no qual a atenção a criança e à sua família não se restringem ao reconhecimento e remissão dos sintomas, mas inclui o oferecimento de um lugar de subjetivação onde, através da produção, a elaboração do mal-estar possa ter lugar. Pela criação e pelo fazer, o fantasiar pode ser vivenciado sem ameaças de culpabilidade paralisante, desagregação e aniquilamento, abrindo espaço para mudanças de posição quanto ao que afeta o sujeito na sua infância (Winnicott, 1969; Dolto, 1981; Mannoni, 1999).

Ressaltamos que o brincar expresso pelo desenhar (Mello, Faschel e Sperb, 1997; Mello, Goulart, Ew e Sperb, 1999) não consistia em um espaço de catarse, 
tampouco era entendido como terapia pelo brincar, mas era focalizado no campo do desejo, da fantasia, da repetição e da elaboração. Os desenhos eram elaborados pelas crianças e pelo analista a partir dos comentários, da insistência com a qual retorna e não pelo desenho em si. As atividades desenvolvidas nas sessões visavam possibilitar o surgimento de sentidos novos, de remanejamentos imaginários dos fatos da realidade. Ratificamos que o trabalho desenvolvido tinha como pressuposto a experiência psicanalítica como possibilidade de incidência sobre o sujeito do inconsciente (Lacan, 1966 /1998).

A atenção precoce à criança e ao sofrimento (Leite, Freire, Pereira e Assadi, 2005) que ela traz no corpo pareceu-nos de grande importância frente às plurais possibilidades de vida que deixariam de ser acessíveis a F.E., especialmente depois dos relatos de seus pais sobre seus ascendentes, denunciando trajetos identificatórios que parecem ter marcado alguns personagens da família materna - traços melancólicos, abortos, câncer em várias pessoas da família - e da paterna - suicídio e algumas tentativas não exitosas.

A consideração do transgeracional impõe-se como fundamental, já que, usando a expressão de Kaës (2000: 46), o pacto denegativo imprime modos organizadores e defensivos dos laços intersubjetivos. As manifestaçôes que colocavam a vida de F.E. em perigo se remetiam às vicissitudes das relações objetais construídas junto aos pais comprometidos pela culpa que impossibilitava o luto e seu doloroso trabalho. Dois bebês aos quais uma mãe, cuja mãe morria, renunciou: o primeiro visto como possível causa de desgosto materno e o segundo como um presente que surgiu com essa incumbência. Muitos foram os dados trazidos e incluídos na história familiar por P., que, aos pouquinhos e na presença da filha, escrevia sua história, assumindo um lugar de autoria.

\section{DE QUE SE CURA UMA CRIANÇA QUE SOFRE DE ASMA?}

A economia das psicopatologias somáticas e seus destinos clínicos conduziram-nos a investir na criação de um espaço transferencial no qual a historização, o brincar e o sonhar deslocavam o que insistia em se repetir, escrevendo-se no corpo orgânico: "o desenhar da criança era visto tal qual o brincar poético de Freud (1909/1976), sendo a articulação entre o brincar e a verbalização uma produção discursiva da criança, possibilitando a intervenção do analista, quando necessária” (Teixeira, 2006b).

$\mathrm{O}$ adoecimento de F.E. trazia à tona a repetição de nomes próprios nãoditos, sufocados na impossibilidade de P. de elaborar a perda dos bebês que abortara. Ela, confrontada com a impossibilidade de sua mãe de fazer o trabalho de 
luto dos bebês e de sua avó, funciona como pára-excitação da mãe. F.E. introjeta a mãe, os bebês mortos e a avó, apresentando-se pelo "sufoco" de ter que carregar em suas entranhas a angústia materna. Não eram raros os atos falhos da mãe que incidiam na execução de certas atividades desencadeadoras das crises asmáticas e das fantasias de F.E., maltratando as barrigas cheias de seus desenhos. A ambivalência materno-filial parecia não ter lugar na fantasia, mostrando-se no enfermar do corpo. Sem expirar, F.E. vivia afogada no ar, gestando sua mãe e seus irmãos que não chegaram a nascer. Nesse sentido, aspectos transgeracionais assumiram importância, marcando as configuraçōes do setting.

A inclusão em uma rede filiatória a partir da qual possa falar ergueu-se como um pilar do trabalho analítico de F.E., possibilitando a escuta do que fere o orgânico como efeito do inconsciente. A desenvoltura de F.E. em seus desenhos foi observada a partir da escuta de seus pais, tomando o lugar da "linguagem orgânica" (Vasse, 1974: 157) e abrindo campo para a fala da mãe. As tramas simbólicas que suportam a inserção de alguém como membro de uma família constituem dispositivos de subjetivação. Os ditos, não-ditos, forçados ou voluntários, e os mal-ditos e mal-entendidos (Rosa, 2000) transmitem-se implicitamente, marcando a lógica dos compromissos familiares, valorados pela culpa e pela dívida próprias às relações de troca.

Seguindo Freud (1909/1976), Lacan (1938/1987: 16-17), ao estudar a novela familiar, a família e seus complexos, aborda as dimensões da hereditariedade psicológica e do parentesco biológico, considerando que a família ocupa uma posição na transmissão da cultura que é essencial para a construção psíquica, ressaltando a importância das ordens geracional e fraterna e das modalidades de transmissão psíquica.

A consideração das possibilidades e implicações dos percursos dos membros da família é enriquecido quando as alternativas construídas no campo do singular são inseridas na lógica dos laços conjugal, parental e fraterno. A análise precoce de F.E. possibilitou a seus pais a reconstrução dos investimentos primários nela, já que eles se deixaram ser despertados como genitores por esse bebê. Como escreveu Winnicott, "um bebê, isso não existe" (Winnicott, 1969: 48), também os pais só existem na relação com o filho. F.E. acalentou sua mãe dentro de si, suportando a dor de uma perda para ela indizível.

\section{CONSIDERAÇÕES FINAIS}

Observamos que as estratégias de cuidado da criança portadora de asma enfatizam os aspectos físicos da enfermidade (Chatkin, Menezes, Albernaz, 2000; 
Fontes, Fonseca, Camargo, Affonso, Calazans, 2005; Lasmar, Goulart, Sakurai, Camargos, 2002; Zhang, Costa, Ávila, Bonfanti, Ferruzzi, 2005), existindo pouca ênfase nos aspectos psicológicos, embora intervenções educativas destinadas a crianças e seus pais ocupem destaque na preocupação dos estudiosos (Howell, Flaim, Lum Lung, 1992). O destaque recai sobre o caráter informativo, e pouca atenção é destinada aos aspectos afetivos das crianças e seus pais, o que, inclusive, dificulta a adesão ao tratamento e o compromisso com o autocuidado.

Goulart e Sperb (2003: 364) ratificam "a necessidade de que se constitua um momento em que as crianças disponham de um espaço para construir histórias, na perspectiva de que, podendo contá-las, possam cada vez mais emergir como sujeitos de sua história”.

O sofrimento põe o sujeito face às impotências, aos limites e à decadência corporal, expondo-o à perspectiva da morte e precipitando defesas e estratégias de enfrentamento que excedem a dimensão do organismo. Entender a clínica à escuta das doenças orgânicas significa concebê-la como invenção do sujeito, como momento em que ele emerge, mesmo que atado às amarras do corpo sofrente e gozante.

A cultura médico-hospitalar permeia o modo de padecimento; no caso de F.E., sua presença foi marcante nas narrativas construídas por sua mãe, denotando os efeitos da racionalidade biomédica (Camargo, 1997; Teixeira, 2002) sobre as hipóteses a respeito da doença da filha. A escuta analítica abriu espaço para a fala, para a construção de narrativas que ficcionem a asma no contexto de vida de crianças e seus pais.

A articulação dos sinais da criança pequena em uma rede simbólica que possibilite os deslocamentos das manifestações psicossomáticas em direção a alternativas outras de reconstituição subjetiva indica-nos que muito há para ser construído em um processo de análise. As intervenções precoces ampliaram a visibilidade dos pais em relação à filha, contribuindo para o redimensionamento dos lugares subjetivos paternos e fraternos, sendo aos pais dada a oportunidade de traçar percursos que, embora ligados aos de seus ascendentes, não sejam cristalizados em elos de inserção filiatória marcados pela dívida, pela culpa, pelo segredo e pela dor, que não permitem o existir.

Acolher o corpo doente significa percorrer um árduo caminho no qual, inicialmente, não há espaços de interrogação sobre a relação da vida com o mal-estar corporal. A construção do setting se dá sobre o reconhecimento de que há algo que fala pelo corpo ator e paciente, que se relaciona a um saber próprio do sujeito que irrompe no corpo, rompendo seu equilíbrio psicossomático; um saber que se inscreve no corpo e que resiste a ser confrontado com a dúvida, com o contraditório e o afetivo do discurso. 
A forte demanda do sujeito portador de doenças orgânicas ao procurar a análise reside na conquista de um cúmplice a mais para a sua dor. $\mathrm{O}$ que podemos oferecer são possibilidades de vida com a angústia e com o mal-estar, possibilidades de repensar a si mesmo na tentativa de não tornar insuportável a já tão irremediável "dor de existir" (Lacan, 1963/1998: 788).

Entender corpo e aparelho psíquico como indistintos é tarefa do analista que trata do padecer da materialidade corpórea. Restabelecer a saúde perfeita constitui um dos ideais da biomedicina, para a qual o Bem almejado é a saúde. Questioná-lo parece ser a via mais lúcida pela qual podemos acolher o sofrimento expresso pelas manifestações orgânicas, sofrimento que demanda o reconhecimento dos afetos e da construção subjetiva da imagem corporal.

$\mathrm{Na}$ clínica, o analista não enfatiza o corpo biológico, apreendendo-o e nele intervindo, através de palavras, "sobre o inconsciente e sobre a história" (Cukiert, 2004: 240), gerando efeitos em um espaço no qual o sofrimento possa se tornar experiência e produzir efeitos na construção subjetiva, nas manifestações da sexualidade e na relação com o outro.

$O$ ethos que suporta as experiências da clínica em seus enfoques dos fenômenos psicossomáticos deve residir na não-exclusão do doloroso e do insuportável da vivência subjetiva, da experimentação do corpo em suas possibilidades nos campos da saúde e da doença, da instalação de enigmas que impliquem o sujeito na ficção de sua história.

O campo da psicossomática parece-nos privilegiado para pensarmos os enigmas que perpassam esse corpo, muitas vezes adoecendo-o, lesionando-o e encaminhando-o à morte sem a implicação do sujeito na história do seu sofrimento. Essas formas de experiência da corporeidade fazem sintoma social e, por isso, precisam ser consideradas quando abordamos as subjetividades contemporâneas e suas implicações clínicas.

\section{REFERÊNCIAS BIBLIOGRÁFICAS}

Berlinck, M. T. (2000). Psicopatologia fundamental. São Paulo: Escuta.

Canguilhem, G. (2000). O normal e o patológico. Rio de Janeiro: Forense Universitária.

Castro, M. da G. de; Andrade, T. M. R. e Muller, M. C. (2006). Conceito mente e corpo através da História. Psicologia em estudo, vol. 11, n 1, 39-43.

Camargo Jr., K. R. de. (1997). A biomedicina. Physis Revista de Saúde Coletiva, 1997, 7, 01, 45-68.

Ceccarelli, P. (2005). O sofrimento psíquico na perspectiva da psicopatologia fundamental. Psicologia em Estudo, vol. 10, nº 3, 471-477. 
Chatkin, M.; Menezes, A. M. B. e Albernaz, E. (2000). Fatores de risco para consultas em pronto-socorro por crianças asmáticas no Sul do Brasil. Rev. Saúde Pública, vol. 34, nº 5, 491-498.

Chiozza, L. A. (1997). Os afetos ocultos em psoríase, asma, transtornos alimentares, varizes. São Paulo: Casa do Psicólogo.

Corrêa, O. B. R. (2001). Os avatares da transmissão psíquica geracional. São Paulo: Escuta.

Cukiert, M. (2004). Consideraçôes sobre o corpo e a linguagem na clínica e na teoria lacaniana. Psicologia USP, vol. 15, n 1-2, jan/jun, 225-241. São Paulo.

Dolto, F. (1981). Au jeu du désir. Paris: Éditions du Seuil. . (1984). L'image inconsciente du corps. Paris: Éditions du Seuil.

Drummond, C. (1995). Função do Imaginário na clínica com crianças. Escola Brasileira de Psicanálise. A imagem rainha (pp. 345-346). Rio de Janeiro: Livraria Sette Letras.

Fontes, M. J. F.; Fonseca, M. T. M.; Camargo, P. A. M.; Affonso, A . G. A. e Calazans, G. M. C. (2005). Asma em menores de cinco anos: dificuldades no diagnóstico e na prevenção da corticoterapia inalatória. Jornal Brasileiro de Pneumologia. vol. 31, nº 3, 244253, São Paulo.

Foucault, M. (2006). O nascimento da clínica. Rio de Janeiro: Forense Universitária.

Freud, S. (1895). Sobre os fundamentos para destacar da neurastenia uma síndrome específica intitulada "neurose de angústia". Edição standard brasileira das obras completas de Sigmund Freud, vol. III. Rio de Janeiro: Imago, 1976.

. (1900). A interpretação dos sonhos. Edição standard brasileira das obras completas de Sigmund Freud, vol. IV. Rio de Janeiro: Imago, 1976.

- (1909 [1908]). Romances familiares. Edição standard brasileira das obras completas de Sigmund Freud, vol. IX. Rio de Janeiro: Imago, 1976.

. (1913). Sobre o início do tratamento. Novas recomendações sobre a técnica da psicanálise I. Edição standard brasileira das obras completas de Sigmund Freud, vol. XII. Rio de Janeiro: Imago, 1976.

. (1914). Sobre o narcisismo: uma introdução. Edição standard brasileira das obras completas de Sigmund Freud, vol. XIV. Rio de Janeiro: Imago, 1976.

. (1915). As pulsões e seus destinos. Edição standard brasileira das obras completas de Sigmund Freud, vol. XIV. Rio de Janeiro: Imago, 1976.

. (1920). Além do princípio de prazer. Edição standard brasileira das obras completas de Sigmund Freud, vol. XVIII. Rio de Janeiro: Imago, 1976.

(1923). O eu e o isso. Edição standard brasileira das obras completas de Sigmund Freud, vol. XIX. Rio de Janeiro: Imago, 1976.

Goulart, C. M. T. e Sperb, T. M. (2003). Histórias de crianças: as narrativas de crianças asmáticas no brincar. Psicologia: reflexão e crítica, vol. 16, nº 2, 355-365. Porto Alegre. Hames, S. L. (1998). Aspectos da psicossomática na infância. São Paulo: Cabral. 
Howell, J. H.; Flaim, T. e Lum Lung, C. (1992). Patient education. Pediatric Clinic of North América, 39, 1343-1361.

Infante, D. P. (1998). O fenômeno psicossomático na infância: notas a partir de um referencial lacaniano. Em Volich, R. M.; Ferraz, F. C. e Arantes, M. A. de A . C. (Orgs.). (1998). Psicossoma II: psicossomática psicanalitica, 147-151. São Paulo: Casa do Psicólogo.

Kaës, R. (2000). Um pacto de resistência intergeracional ao luto. Em Correa, O. B. R. (Org.). (2000). Os avatares da transmissão psíquica geracional, 45-59. São Paulo: Escuta.

Kreisler, L. (1983). La psychanalyse de l'enfant. Paris: PUF.

- (1999). A nova criança da desordem psicossomática. São Paulo: Casa do Psicólogo.

Kupfer, M. C. M. e Voltolini, R. (2005). Uso de indicadores em pesquisas de orientação psicanalítica: um debate conceitual. Psicologia: Teoria e Prática, vol. 21, nº 3, 359-364. Brasília.

Lacan, J. (1938). A família. Lisboa: Assírio \& Alvim, 1987.

- (1963). Kant com Sade. Em Escritos (pp. 776-803). Rio de Janeiro: Jorge Zahar, 1998.

. (1966). O estádio do espelho como formador da função do eu. Em Escritos (pp. 96-103). Rio de Janeiro: Jorge Zahar, 1998.

Lasmar, L; Goulart, E.; Sakurai, E. e Camargos, P. (2002). Fatores de risco para hospitalização de crianças e adolescentes asmáticos. Rev. Saúde Pública, vol. 36, no 4, 409-419.

Leite, A. C. de C.; Freire, J. G.; Pereira, M. E. C. e Assadi, T. C. (2003). O menino e o efeito pirilampo: um estudo em psicossomática. Agora, vol. 6, nº 1, 99-114. Rio de Janeiro: UFRJ.

Mannoni, M. (1999). A criança retardada e a mãe. Rio de Janeiro: Martins Fontes.

Meira, Y. M. (2003). O porão da família. São Paulo: Casa do Psicólogo.

Mello, C. O.; Faschel, J. e Sperb, T. M. (1997). A interação social na brincadeira de faz-deconta: uma análise da dimensão metacomunicativa. Psicologia: teoria e pesquisa, 13, 119-130.

Mello, C. O.; Goulart, C. M. T.; Ew, R. A. e Sperb, T. M. (1999). Brincar no hospital: assunto para discutir e praticar. Psicologia: Teoria e Pesquisa, 15, 65-74.

Mello Filho, J. de. (1992). Psicossomática hoje. Porto Alegre: ArtMed. . (2004). Doença e família. São Paulo: Casa do Psicólogo.

Rosa, M. D. (2000). Histórias que não se contam: o não-dito e a psicanálise com crianças e adolescentes. Taubaté, São Paulo: Cabral Editora Universitária.

Teixeira, L. C. (2002). Os lugares do sofrimento e do processo de cura entre medicina e psicanálise: reflexões sobre a iatrogenia. Universa: ciências biológicas e da saúde e médicas, vol. $1, \mathrm{n}^{\circ} 1,81-94$. 
. (2006a). Um corpo que dói: consideraçôes sobre a clínica psicanalítica dos fenômenos psicossomáticos. Latin-American Journal of Fundamental Psychopathology on line, vol. $6, \mathrm{n}^{\circ} 1$.

. (2006b). Intervenção psicanalítica em grupo em uma clínica-escola: considerações teórico-clínicas. In mimeo.

Vasse, D. (1974). L'ombilic et la voix. Paris: Seuil.

Volich, R. M. e Ferraz, F. C. (1998). Psicossoma. São Paulo: Casa do Psicólogo.

Winnicott, D. (1969). De la pediatrie à la psychanalyse. Paris: Payot.

Zhang, L; Costa, M. G.; Ávila, L. H.; Bonfati, T. e Ferruzzi, E. H. (2005). Conhecimentos de pais de crianças asmáticas sobre a doença no momento da admissão a um serviço especializado. Rev. Assoc. Med. Bras., dez 2005, vol. 51, nº 6, 342-347.

Recebido em 3 de abril de 2006

Aceito para publicação em 30 de setembro de 2006 